Washington University School of Medicine Digital Commons@Becker

\title{
Trial of short-course antimicrobial therapy for intraabdominal infection
}

\author{
J E. Mazuski \\ Washington University School of Medicine in St. Louis \\ et al
}

Follow this and additional works at: https://digitalcommons.wustl.edu/open_access_pubs Please let us know how this document benefits you.

\section{Recommended Citation}

Mazuski, J E. and et al, "Trial of short-course antimicrobial therapy for intraabdominal infection." The New England Journal of Medicine. 372, 21. 1996-2005. (2015).

https://digitalcommons.wustl.edu/open_access_pubs/3899

This Open Access Publication is brought to you for free and open access by Digital Commons@Becker. It has been accepted for inclusion in Open Access Publications by an authorized administrator of Digital Commons@Becker. For more information, please contact vanam@wustl.edu. 


\section{Trial of Short-Course Antimicrobial Therapy for Intraabdominal Infection}

\author{
R.G. Sawyer, J.A. Claridge, A.B. Nathens, O.D. Rotstein, T.M. Duane, H.L. Evans, \\ C.H. Cook, P.J. O'Neill, J.E. Mazuski, R. Askari, M.A. Wilson, L.M. Napolitano, \\ N. Namias, P.R. Miller, E.P. Dellinger, C.M. Watson, R. Coimbra, D.L. Dent, \\ S.F. Lowry,* C.S. Cocanour, M.A. West, K.L. Banton, W.G. Cheadle, \\ P.A. Lipsett, C.A. Guidry, and K. Popovsky
}

ABSTRACT
The authors' full names, academic degrees, and affiliations are listed in the Appendix. Address reprint requests to Dr. Sawyer at the Department of Surgery, University of Virginia Health System, Box 800709, Charlottesville, VA 22908-0709, or at rws2k@virginia.edu.

*Deceased.

N Engl J Med 2015;372:1996-2005. DOI: 10.1056/NEJMoal411162

Copyright @ 2015 Massachusetts Medical Society. 
OMPLICATED INTRAABDOMINAL INFECtion continues to be a common problem worldwide. Approximately 300,000 cases of appendicitis occur each year in the United States, ${ }^{1}$ and at least twice that many cases of non-appendiceal infection require management. ${ }^{2}$ Morbidity ranges from $5 \%$ among patients evaluated in broad observational studies ${ }^{2-4}$ to close to $50 \%$ in some cohorts, such as the elderly or critically ill. ${ }^{5,6}$ Despite the diversity of specific processes in these infections, the basic tenets of management are similar: resuscitate patients who have the systemic inflammatory response syndrome (SIRS), control the source of contamination, remove most of the infected or necrotic material, and administer antimicrobial agents to eradicate residual pathogens. ${ }^{7,8}$

Antimicrobial therapy for the management of intraabdominal infections continues to evolve. Published guidelines include recommendations for appropriate antimicrobial agents on the basis of high-quality evidence. ${ }^{7,8}$ The appropriate duration of therapy, however, remains unclear. Traditionally, practitioners have treated patients until all evidence of SIRS has resolved, typically for 7 to 14 days. More recently, it has been suggested that with adequate source control, a shorter course of 3 to 5 days should suffice for cure ${ }^{9}$ and could decrease the risk of antimicrobial resistance. Currently used guidelines, including those published jointly by the Surgical Infection Society (SIS) and the Infectious Diseases Society of America (IDSA), recommend a treatment course of 4 to 7 days, depending on the clinical response.,8

Despite these recommendations, observational studies show that therapy is typically administered for 10 to 14 days. ${ }^{4,10,11}$ One reason that shortening therapy has been difficult is the $20 \%$ rate of clinically significant infectious complications after treatment. ${ }^{3}$ These subsequent complications, however, are often due to progression of the original disease or inadequate original source control and may not be preventable with antimicrobial therapy alone.

We conducted the randomized Study to Optimize Peritoneal Infection Therapy (STOP-IT) trial to compare two strategies guiding the duration of antimicrobial therapy for the management of complicated intraabdominal infection. We hypothesized that the administration of fixed-duration antibiotic therapy (4 days) after source control would lead to equivalent outcomes and a shorter duration of therapy as compared with the tradi- tional strategy of administration of antibiotics until 2 days after the resolution of the physiological abnormalities related to SIRS.

\section{METHODS}

\section{STUDY POPULATION}

Patients were eligible for enrollment in the study if they were 16 years of age or older; if they presented with a complicated intraabdominal infection with either fever (temperature $\geq 38.0^{\circ} \mathrm{C}$ ), leukocytosis $(\geq 11,000$ peripheral white cells per cubic millimeter), or gastrointestinal dysfunction due to peritonitis precluding intake of more than half their normal diet; and if they had undergone an intervention to achieve source control.

Source control, defined as procedures that eliminate infectious foci, control factors that promote ongoing infection, and correct or control anatomical derangements to restore normal physiological function, is critical to the management of any infection. ${ }^{12}$ The adequacy of source control was confirmed by the local investigator and the principal investigator of the overall study (see the full protocol, available with the full text of this article at NEJM.org).

\section{STUDY DESIGN AND OVERSIGHT}

In this investigator-initiated, open-label, multicenter trial, we randomly assigned participants in a 1:1 ratio to receive 4 full days of antimicrobial therapy after their index source-control procedure (experimental group) or to receive antimicrobial therapy until 2 days after the resolution of the physiological abnormalities related to SIRS (control group). This resolution was defined as a body temperature of less than $38.0^{\circ} \mathrm{C}$ for 1 entire calendar day, normalization of the peripheral white-cell count to less than 11,000 per cubic millimeter, and the patient's ability to consume more than half of his or her regular diet without adverse effects.

All the patients or their legal surrogates provided written informed consent. The specific choice of antimicrobial agents was not dictated by the protocol but rather was considered to be acceptable if it was consistent with published SIS-IDSA guidelines. ${ }^{7,8}$

Randomization was performed with the use of a Web-based data system managed by Merge Healthcare, an independent contract research organization paid by the sponsor. Each study site

\section{回:}

A Quick Take summary is available at NEJM.org 
used a unique randomization sequence. Only 20 patients with appendiceal disease were permitted in each sequential block of 200 randomly assigned patients. Patients were enrolled at 23 sites throughout the United States and Canada, and the study was coordinated through the SIS and managed by the University of Virginia team. The protocol was approved by the institutional review board at each site. All the authors vouch for the accuracy and completeness of the data, the analyses reported here, and the fidelity of the study to the protocol.

\section{DURATION OF THERAPY AND ADHERENCE} TO THE PROTOCOL

After randomization, patients were followed to assess their clinical course and adherence to the protocol. In the control group, adherence to the protocol was defined as the receipt of appropriate antimicrobial agents until $2 \pm 1$ calendar days after the first day that the patient had a maximum temperature of less than $38.0^{\circ} \mathrm{C}$ for 1 whole calendar day, less than 11,000 peripheral white cells per cubic millimeter, and the ability to meet more than half their nutritional needs enterally. A maximum of 10 days of therapy was allowed for treatment of the initial intraabdominal infection.

In the experimental group, adherence to the protocol was defined as the receipt of effective antimicrobial agents for $4 \pm 1$ calendar days after the index source-control procedure. Patients were followed for 30 days after the initial source-control procedure and assessed for infectious complications, use of antimicrobial therapy, and death from any cause. Patients hospitalized for more than 30 days were followed to determine hospital length of stay. A resistant pathogen was defined as methicillin-resistant Staphylococcus aureus, any vancomycin-resistant enterococcus species, or a gram-negative organism that was resistant to all members of a major class of antimicrobial agents.

\section{STATISTICAL ANALYSIS}

The primary analysis compared the proportion of patients in each group in whom a surgical-site infection or recurrent intraabdominal infection developed or in whom death occurred within 30 days after the index source-control procedure. Analyses were performed with the use of the chi-square test with Yates' correction, Student's t-test, or Wil- coxon signed-rank test, where applicable, in the intention-to-treat population, which consisted of all patients who provided consent and underwent randomization. Kaplan-Meier curves for time to an event were constructed and compared with the use of the log-rank test.

Secondary analyses assessed the duration of antimicrobial therapy for the index infection, overall exposure to antimicrobial agents, rates of subsequent extraabdominal infection, and adherence to the protocol. Prespecified subgroups for analysis included patients with an Acute Physiology and Chronic Health Evaluation (APACHE) II score of 10 or higher (on a scale of 0 to 71 , with higher scores indicating an increased risk of death), patients with a health care-associated infection, patients with an appendiceal source of index infection and those with a non-appendiceal source of index infection, and patients with an index infection treated by surgical drainage and those whose index infection was treated by percutaneous drainage. Multivariate logistic regression was performed to determine associations with the composite outcome, including key demographic variables and treatment-group assignments.

According to the original sample-size calculation to define equivalence between the two groups, we calculated that a sample of 505 patients per group would be required to give the study $90 \%$ power to detect a $10 \%$ difference in complication rates, assuming a 30\% complication rate among controls and assuming a dropout rate of $10 \%$, at an alpha level of 0.05 . After the first interim analysis showed nearly identical outcomes in the two cohorts, a competitive renewal request for continued support to reach the targeted enrollment levels was not funded owing largely to a concern for futility.

\section{RESULTS}

\section{PATIENT CHARACTERISTICS AND INDEX INFECTIONS}

From August 2008 through August 2013, a total of 518 patients underwent randomization. One patient withdrew consent after randomization. Thirty-day follow-up was completed in $99.8 \%$ of the patients (Fig. 1).

The mean $( \pm S E)$ age of the patients was $52.2 \pm 1.0$ years (range, 16 to 88 ); most of the patients were male, and the composition of racial and ethnic groups was similar in the two groups. 


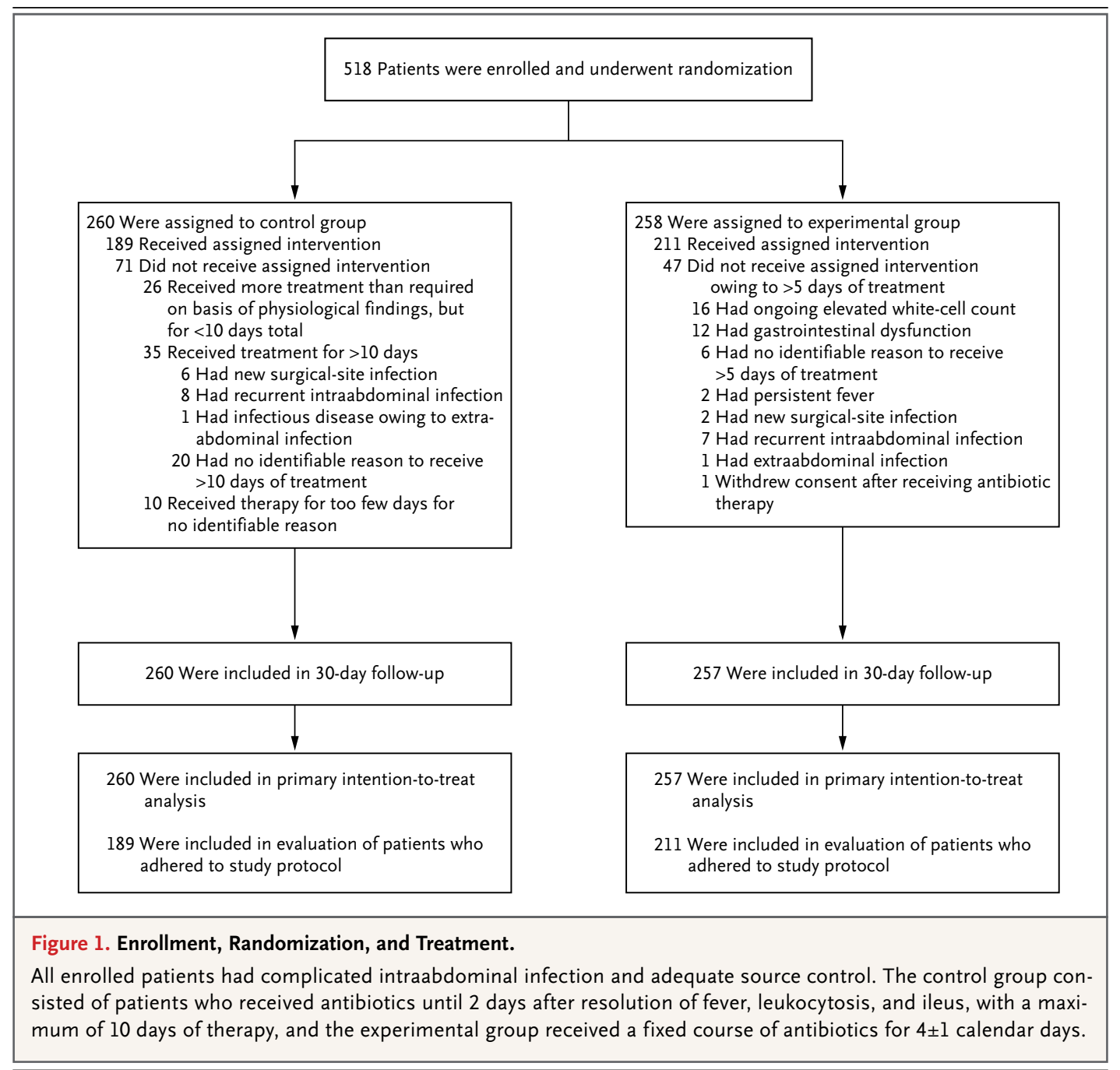

The mean APACHE II score for the index infection was $10.1 \pm 0.3$ (range, 0 to 29 ), the most common origin of the infection was the colon or rectum, and one third of the infections were treated with a percutaneous procedure (Table 1). Complete demographic data are provided in Table S1 in the Supplementary Appendix, available at NEJM .org. There were no differences between the two study groups, at a significance level of less than 0.05 , with respect to any demographic variable.

\section{ADHERENCE TO THE PROTOCOL}

A total of 211 of 258 patients in the experimental group (81.8\%), as compared with 189 of 260 patients in the control group (72.7\%), ultimately received antimicrobial therapy for the protocolspecified duration ( $\mathrm{P}=0.02)$ (Fig. 1). In the control group, 10 patients received therapy for too few days, including 7 patients who continued to have an elevated white-cell count and 4 patients who had ongoing gastrointestinal dysfunction when therapy was discontinued. Among the other patients who did not receive the assigned therapy, 26 received therapy for less than 10 days (but longer than required according to their physiological findings) and 35 received therapy for more than 10 days. In some patients in the control group, the initial course of antimicrobial therapy was extended owing to a second infection, and they were considered to be in violation of the protocol; 6 of these patients had a surgical-site infection, 8 had a recurrent intraabdominal infection, and 1 had an infectious disease owing to extraabdominal infection.

In the experimental group, all 47 patients who did not adhere to the protocol received a treat- 


\begin{tabular}{|c|c|c|}
\hline Variable & $\begin{array}{l}\text { Control } \\
\text { Group } \\
(\mathrm{N}=\mathbf{2 6 0})\end{array}$ & $\begin{array}{c}\text { Experimenta } \\
\text { Group } \\
(\mathrm{N}=\mathbf{2 5 8})\end{array}$ \\
\hline Age $-y r$ & $52.2 \pm 1.0$ & $52.2 \pm 1.0$ \\
\hline Male sex - no. (\%) & $145(55.8)$ & $144(55.8)$ \\
\hline \multicolumn{3}{|l|}{ Race or ethnic group - no. $(\%) \dagger$} \\
\hline White & $208(80.0)$ & $196(76.0)$ \\
\hline Black & $43(16.5)$ & $51(19.8)$ \\
\hline Asian & $5(1.9)$ & $6(2.3)$ \\
\hline American Indian or Alaskan Native & $2(0.8)$ & $1(0.4)$ \\
\hline Hispanic — no. (\%) & $20(7.7)$ & $15(5.8)$ \\
\hline Other & $2(0.8)$ & $4(1.6)$ \\
\hline \multicolumn{3}{|l|}{ Characteristics of index infection } \\
\hline APACHE II score & $9.9 \pm 0.4$ & $10.3 \pm 0.4$ \\
\hline Maximum white-cell count - per $\mathrm{mm}^{3}$ & $15,600 \pm 0.4$ & $17,100 \pm 0.7$ \\
\hline Maximum body temperature $-{ }^{\circ} \mathrm{C}$ & $37.8 \pm 0.1$ & $37.7 \pm 0.1$ \\
\hline \multicolumn{3}{|l|}{ Organ of origin - no. (\%) } \\
\hline Colon or rectum & $80(30.8)$ & $97(37.6)$ \\
\hline Appendix & $34(13.1)$ & $39(15.1)$ \\
\hline Small bowel & $31(11.9)$ & $42(16.3)$ \\
\hline \multicolumn{3}{|l|}{ Source-control procedure - no. (\%) } \\
\hline Percutaneous drainage & $86(33.1)$ & $86(33.3)$ \\
\hline Resection and anastomosis or closure & $69(26.5)$ & $64(24.8)$ \\
\hline Surgical drainage only & $55(21.2)$ & $54(20.9)$ \\
\hline Resection and proximal diversion & $27(10.4)$ & $37(14.3)$ \\
\hline Simple closure & $20(7.7)$ & $12(4.7)$ \\
\hline Surgical drainage and diversion & $3(1.2)$ & $4(1.6)$ \\
\hline
\end{tabular}

* Plus-minus values are means $\pm S E$. There were no significant differences between the groups $(P<0.05)$.

$\uparrow$ Race and ethnic groups were reported by the patient or surrogate.

$\checkmark$ Acute Physiology and Chronic Health Evaluation (APACHE) II scores range from 0 to 71, with higher scores indicating an increased risk of death.

ment course that was longer than the duration specified in the protocol. Of these patients, 16 had an ongoing elevated white-cell count, 2 had persistent fever, and 12 continued to have gastrointestinal dysfunction that prevented enteral intake. A new infection leading to extension of antimicrobial therapy for more than 4 days occurred in 10 patients, including 2 with a surgical-site infection, 7 with a recurrent intraabdominal infection, and 1 with an extraabdominal infection. Two patients with recurrent intraabdominal infection also had a persistently elevated white-cell count.

\section{PRIMARY AND MAJOR SECONDARY OUTCOMES}

The composite primary end point of surgical-site infection, recurrent intraabdominal infection, or death occurred in 56 of 257 patients in the experimental group (21.8\%), as compared with 58 of 260 patients in the control group (22.3\%) (absolute difference, -0.5 percentage point, $95 \%$ confidence interval $[\mathrm{CI}],-7.0$ to $8.0 ; \mathrm{P}=0.92$ ) (Table 2). Kaplan-Meier analysis showed no significant between-group difference in the time to the composite primary outcome (Fig. 2).

No significant between-group differences were seen in the rates of the individual primary-endpoint components of surgical-site infection (absolute difference, -2.2 percentage points; $95 \% \mathrm{CI}$, -2.4 to $7.0 ; \mathrm{P}=0.43$ ), recurrent intraabdominal infection (absolute difference, 1.8 percentage points; $95 \% \mathrm{CI},-4.5$ to $7.8 ; \mathrm{P}=0.67$ ), and death (absolute difference, 0.4 percentage point; $95 \% \mathrm{CI},-1.7$ to 2.7; $\mathrm{P}=0.99$ ). Diagnosis of surgical-site infection and recurrent intraabdominal infection, but not death, occurred significantly later in the control group than in the experimental group (Table 2). Death occurred in 5 of the 518 patients in the two groups combined $(1.0 \%, 2$ patients in the control group and 3 patients in the experimental group) at a mean of $18.7 \pm 0.4$ days after the index source-control procedure. All the deaths were judged by the site principal investigator and the study principal investigator to be related to underlying coexisting diseases (principally cancer and cardiovascular disease) and not to the initial intraabdominal infection.

The median duration of antimicrobial treatment for the index intraabdominal infection was 4.0 days (interquartile range, 4.0 to 5.0 ) in the experimental group, as compared with 8.0 days (interquartile range, 5.0 to 10.0 ) in the control group (absolute difference, -4.0 days; $95 \% \mathrm{CI}$, -4.7 to $-3.3 ; \mathrm{P}<0.001)$. There were significantly fewer median antimicrobial-free days at 30 days (including all antimicrobial therapy) in the control group than in the experimental group. No significant between-group differences were found with respect to the rates of extraabdominal infection, Clostridium difficile infection, or secondary infections with resistant pathogens (Table 2).

\section{OUTCOMES IN PRESPECIFIED SUBGROUPS}

The occurrence of the primary composite outcome was similar in the two study groups in all prespecified subgroups, including patients who were 


\begin{tabular}{|c|c|c|c|}
\hline Variable & $\begin{array}{l}\text { Control } \\
\text { Group } \\
(\mathrm{N}=\mathbf{2 6 0})\end{array}$ & $\begin{array}{c}\text { Experimental } \\
\text { Group } \\
(\mathrm{N}=257)\end{array}$ & P Value \\
\hline $\begin{array}{l}\text { Primary outcome: surgical-site infection, recurrent intraabdominal } \\
\text { infection, or death - no. (\%) }\end{array}$ & $58(22.3)$ & $56(21.8)$ & 0.92 \\
\hline Surgical-site infection & $23(8.8)$ & $17(6.6)$ & 0.43 \\
\hline Recurrent intraabdominal infection & $36(13.8)$ & $40(15.6)$ & 0.67 \\
\hline Death & $2(0.8)$ & $3(1.2)$ & 0.99 \\
\hline \multicolumn{4}{|l|}{ Time to event - no. of days after index source-control procedure } \\
\hline Diagnosis of surgical-site infection & $15.1 \pm 0.6$ & $8.8 \pm 0.4$ & $<0.001$ \\
\hline Diagnosis of recurrent intraabdominal infection & $15.1 \pm 0.5$ & $10.8 \pm 0.4$ & $<0.001$ \\
\hline Death & $19.0 \pm 1.0$ & $18.5 \pm 0.5$ & 0.66 \\
\hline \multicolumn{4}{|l|}{ Secondary outcome } \\
\hline $\begin{array}{l}\text { Surgical-site infection or recurrent intraabdominal infection with } \\
\text { resistant pathogen }- \text { no. (\%) }\end{array}$ & $9(3.5)$ & $6(2.3)$ & 0.62 \\
\hline \multicolumn{4}{|l|}{ Site of extraabdominal infection — no. (\%) } \\
\hline Any site $\nmid$ & $13(5.0)$ & $23(8.9)$ & 0.11 \\
\hline Urine & $10(3.8)$ & $13(5.1)$ & 0.65 \\
\hline Blood & $3(1.2)$ & $5(1.9)$ & 0.71 \\
\hline Lung & $3(1.2)$ & $3(1.2)$ & 0.99 \\
\hline Area of skin other than surgical site & $1(0.4)$ & $4(1.6)$ & 0.36 \\
\hline Vascular catheter & $0(0)$ & $2(0.8)$ & 0.47 \\
\hline Clostridium difficile infection — no. (\%) & $3(1.2)$ & $5(1.9)$ & 0.71 \\
\hline Extraabdominal infection with resistant pathogen - no. (\%) & $6(2.3)$ & $2(0.8)$ & 0.29 \\
\hline \multicolumn{4}{|l|}{ Duration of outcome - days } \\
\hline Antimicrobial therapy for index infection & & & $<0.001$ \\
\hline Median & 8 & 4 & \\
\hline Interquartile range & $5-10$ & $4-5$ & \\
\hline Antimicrobial-free days at 30 days & & & $<0.001$ \\
\hline Median & 21 & 25 & \\
\hline Interquartile range & $18-25$ & $21-26$ & \\
\hline Hospitalization after index procedure & & & 0.48 \\
\hline Median & 7 & 7 & \\
\hline Interquartile range & $4-11$ & $4-11$ & \\
\hline Hospital-free days at 30 days & & & 0.22 \\
\hline Median & 23 & 22 & \\
\hline Interquartile range & $18-26$ & $16-26$ & \\
\hline
\end{tabular}

* Plus-minus values are means $\pm \mathrm{SE}$.

$\uparrow$ Some patients had extraabdominal infections at more than one site.

treated per protocol (33 of 189 patients in the control group [17.5\%] and 37 of 211 patients in the experimental group [17.5\%]; absolute difference, 0.1 percentage point; $95 \% \mathrm{CI},-7.4$ to 7.6 ; $\mathrm{P}=0.72$ ) (Fig. 3, and Table S2 in the Supplemen- tary Appendix). Differences in the duration of therapy among patients in all subgroups were similar to those seen in the intention-to-treat analysis, with the exception of the subgroup of patients who were not treated according to the 


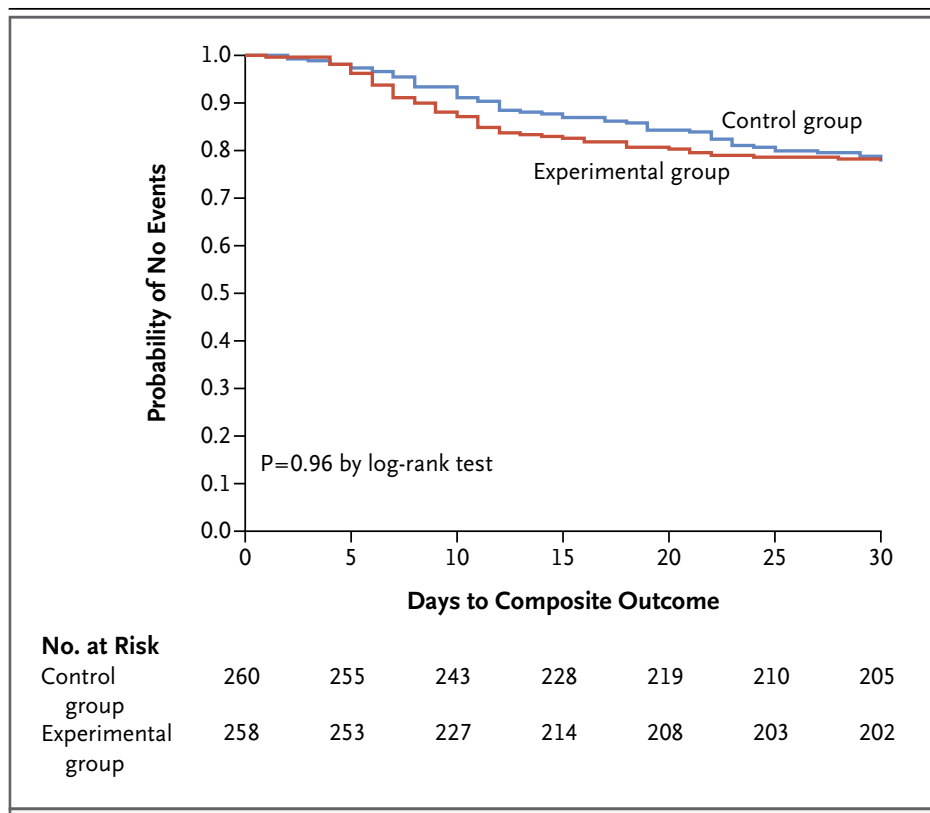

Figure 2. Kaplan-Meier Time-to-Event Curves for the Composite Primary Outcome, According to Treatment Group.

The composite primary outcome was surgical-site infection, recurrent intraabdominal infection, or death.

protocol, for whom the median duration was 11 days in both groups. Results of the logisticregression analysis are provided in Table $\mathrm{S} 3$ in the Supplementary Appendix; there was no significant interaction between treatment groups and the primary composite outcome.

DISCUSSION

In this randomized study involving patients with complicated intraabdominal infections, a fixed duration of 4 days of antibiotic treatment resulted in outcomes that were similar to those of a traditional, longer course that was based on resolution of physiological abnormalities, and the shorter course was associated with significantly fewer days of antibiotic exposure. These data provide support for the concept that after an adequate source-control procedure, the beneficial effects of systemic antimicrobial therapy are limited to the first few days after intervention. In addition, it might be argued that the delay in manifestation of infectious complications in the control group was itself an adverse outcome, since the time to recognition of these events and, therefore, the overall time to resolution of all infections was prolonged.
Traditionally, physicians have administered antimicrobial therapy in patients who have intraabdominal infections until clinical and laboratory evidence suggests that the infection has resolved. They reasoned that ongoing sepsis was indicative of ongoing replication of pathogens. More recent experimental data, however, suggest that a prolonged SIRS may be more a reflection of host immune activity than an indication of the presence of viable microorganisms. ${ }^{13-15}$ As such, efforts have begun to shorten the duration of antimicrobial therapy in the presence of traditional markers of sepsis. These efforts have already been successful in other severe infections such as ventilator-associated pneumonia. ${ }^{16}$

Currently, the average duration of antibiotic therapy for intraabdominal infection is 10 to 14 days.,10,11 The results of smaller studies of the effect of an abbreviated course of antimicrobial therapy have been published. Schein et al. reported on an uncontrolled study in which 23 consecutive patients with diffuse peritonitis were assigned to receive 3 to 5 days of antibiotics. ${ }^{9}$ Infections developed in $22 \%$ of these patients; these rates were similar to those seen in a historical cohort. Basoli et al., who randomly assigned 90 patients with mild-to-moderate intraabdominal infection to either 3 days or 5 or more days of ertapenem therapy, found no between-group difference in infectious outcomes. ${ }^{17}$ Those findings, however, are not generalizable to the majority of patients with intraabdominal infection, since half the patients had appendiceal disease and the overall rate of infectious complications was less than $10 \%$. As compared with these studies, the STOP-IT trial had several advantages, including a larger sample size, randomized design, and enrollment of patients with a broader range of severity of illness.

The rate of infectious complications was more than $20 \%$ in both groups of our study, and most of these complications were recurrent intraabdominal infections. Given the large difference in the number of days of treatment in the two study groups, neither shortening nor lengthening the duration of antimicrobial therapy appears likely to affect infectious outcomes. Truly clinically significant improvement in the management of this disease, therefore, probably awaits more effective technical or immune response-modifying interventions. However, the observed mortality in our study was only $1 \%$; this is better than anticipated among patients with a mean APACHE II score 


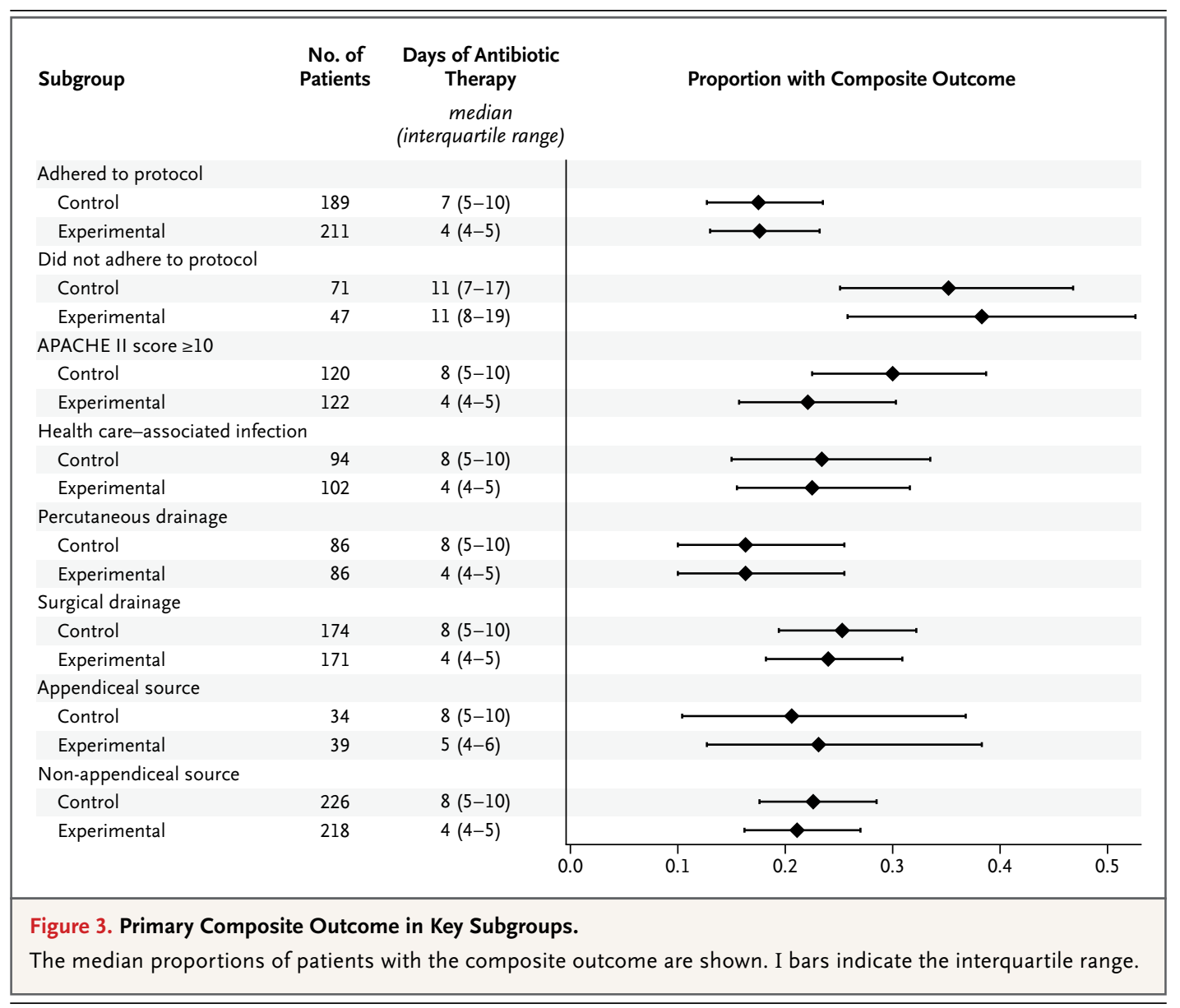

of 10 and is perhaps related to the reduction in mortality from many serious infections noted after the initiation of the Surviving Sepsis Campaign. ${ }^{18}$

Strengths of the trial include the inclusion of 23 centers and the similarity in outcomes between the control group and the experimental group in a wide variety of important, prespecified subgroups. For example, although rates of complications differed according to the severity of illness and the method of source control (percutaneous vs. surgical drainage), the effect size was similar in the two study groups. These findings suggest that the results may well be generalizable across a wide array of patient populations, care settings, and interventions, as long as adequate source control is first achieved.

Several limitations to the interpretation of these data are worth noting. First, patients without adequate source control were excluded, and only a small number of patients with immunosuppression were included; it remains unclear whether these populations would benefit from a longer duration of therapy. Second, the rate of nonadherence to the protocol was moderately high, including $18 \%$ of patients in the experimental group; this created bias toward the null hypothesis of no difference in therapy, though the fact that the per-protocol population had similar complication rates between the experimental and control groups is reassuring. Finally, the original calculated sample size to assert equivalence between groups was not achieved and proof of equivalence cannot be claimed, although the $95 \%$ confidence interval for the difference in event rates was -7.0 to 8.0 and provides encouraging evidence that the true difference is less than $10 \%$. In other words, the null hypothesis of equal efficacy cannot be rejected.

In conclusion, outcomes in patients with intraabdominal infections who have undergone a successful source-control procedure and receive a fixed, 4-day course of antimicrobial therapy appear to be generally similar to outcomes in pa- 
tients in whom systemic antimicrobial agents are administered until after the resolution of signs and symptoms of sepsis.

Presented in part at the 34th Annual Meeting of the Surgical Infection Society, Baltimore, May 1-3, 2014.

Supported by grants (R01GM081510 and T32 AI078875) from the National Institutes of Health.

Dr. Sawyer reports receiving consulting fees from $3 \mathrm{M}$ and Pfizer; Dr. Duane, lecture fees from Pfizer; Dr. O'Neill, fees for serving on a surgical review panel for Cubist; Dr. Mazuski, fees for serving on advisory boards from AstraZeneca, Cubist, Merck, and Pfizer, consulting fees from Bayer, lecture fees from Merck, and grant support from AstraZeneca, Bayer, Merck, and Pfizer; and Dr. Dellinger, fees for serving on advisory boards from Merck, Baxter, Ortho-McNeil, Targanta Therapeutics, ScheringPlough, Astellas, CareFusion, Durata Therapeutics, Pfizer, Rib-X Pharmaceuticals, Affinium Pharmaceuticals, Tetraphase Pharmaceuticals, and R-Pharm, and lecture fees from Applied Medical. No other potential conflict of interest relevant to this article was reported.

Disclosure forms provided by the authors are available with the full text of this article at NEJM.org.

APPENDIX

The authors' full names and academic degrees are as follows: Robert G. Sawyer, M.D., Jeffrey A. Claridge, M.D., Avery B. Nathens, M.D., Ori D. Rotstein, M.D., Therese M. Duane, M.D., Heather L. Evans, M.D., Charles H. Cook, M.D., Patrick J. O'Neill, M.D., Ph.D., John E. Mazuski, M.D., Ph.D., Reza Askari, M.D., Mark A. Wilson, M.D., Lena M. Napolitano, M.D., Nicholas Namias, M.D., Preston R. Miller, M.D., E. Patchen Dellinger, M.D., Christopher M. Watson, M.D., Raul Coimbra, M.D., Daniel L. Dent, M.D., Stephen F. Lowry, M.D., Christine S. Cocanour, M.D., Michaela A. West, M.D., Ph.D., Kaysie L. Banton, M.D., William G. Cheadle, M.D., Pamela A. Lipsett, M.D., Christopher A. Guidry, M.D., and Kimberley Popovsky, B.S.N.

The authors' affiliations are as follows: the Department of Surgery, University of Virginia Health System, Charlottesville (R.G.S., C.A.G., K.P.); the Department of Surgery, Virginia Commonwealth University, Richmond (T.M.D.); the Department of Surgery, Case Western Reserve University, Cleveland (J.A.C.); the Department of Surgery, University of Toronto, Toronto (A.B.N., O.D.R.); the Department of Surgery, University of Washington, Seattle (H.L.E., E.P.D.); the Department of Surgery, Beth Israel Deaconess Medical Center (C.H.C.), and the Department of Surgery, Brigham and Women's Hospital (R.A.) - both in Boston; the Department of Surgery, Maricopa Integrated Health System, Phoenix, AZ (P.J.O.); the Department of Surgery, Washington University, St. Louis (J.E.M.); the Department of Surgery, VA Pittsburgh Healthcare System, Pittsburgh (M.A. Wilson); the Department of Surgery, University of Michigan, Ann Arbor (L.M.N.); the Department of Surgery, University of Miami Miller School of Medicine, Miami (N.N.); the Department of Surgery, Wake Forest School of Medicine, Winston-Salem, NC (P.R.M.); the Department of Surgery, University of South Carolina, Columbia (C.M.W.); University of California, San Diego, San Diego (R.C.), the Department of Surgery, UC Davis Medical Center, Sacramento (C.S.C.), and the Department of Surgery, University of California, San Francisco, San Francisco (M.A. West) - all in California; the Department of Surgery, University of Texas Health Science Center at San Antonio, San Antonio (D.L.D.); the Department of Surgery, University of Medicine and Dentistry of New Jersey, Newark (S.F.L.); the Department of Surgery, University of Minnesota Medical School, Minneapolis (K.L.B.); the Department of Surgery, University of Louisville School of Medicine, Louisville, KY (W.G.C.); and the Department of Surgery, Johns Hopkins University School of Medicine, Baltimore (P.A.L.).

\section{REFERENCES}

1. DeFrances CJ, Cullen KA, Kozak LJ. National Hospital Discharge Survey: 2005 annual summary with detailed diagnosis and procedure data. Vital Health Stat 13 2007;165:1-209.

2. Sartelli M, Catena F, Ansaloni L, et al. Complicated intra-abdominal infections worldwide: the definitive data of the CIAOW Study. World J Emerg Surg 2014;9:37.

3. Inui $\mathrm{T}$, Haridas $\mathrm{M}$, Claridge JA, Malangoni MA. Mortality for intra-abdominal infection is associated with intrinsic risk factors rather than the source of infection. Surgery 2009;146:654-61.

4. Riccio LM, Popovsky KA, Hranjec T, et al. Association of excessive duration of antibiotic therapy for intra-abdominal infection with subsequent extra-abdominal infection and death: a study of 2,552 consecutive infections. Surg Infect (Larchmt) 2014;15:417-24.

5. Christou NV, Barie PS, Dellinger EP, Waymack JP, Stone HH. Surgical Infection Society intra-abdominal infection study: prospective evaluation of management techniques and outcome. Arch Surg 1993;128:193-8.

6. Dupont H, Friggeri A, Touzeau J, et al. Enterococci increase the morbidity and mortality associated with severe intra-abdominal infections in elderly patients hospitalized in the intensive care unit. J Antimicrob Chemother 2011;66 2379-85.

7. Solomkin JS, Mazuski JE, Bradley JS et al. Diagnosis and management of complicated intra-abdominal infection in adults and children: guidelines by the Surgical Infection Society and the Infectious Diseases Society of America. Surg Infect (Larchmt) 2010;11:79-109.

8. Solomkin JS, Mazuski JE, Bradley JS, et al. Diagnosis and management of complicated intra-abdominal infection in adults and children: guidelines by the Surgical Infection Society and the Infectious Diseases Society of America. Clin Infect Dis 2010; 50:133-64.

9. Schein M, Assalia A, Bachus H. Minimal antibiotic therapy after emergency abdominal surgery: a prospective study. Br J Surg 1994;81:989-91.

10. Guirao X, Sánchez García M, Bassett $M$, et al. Safety and tolerability of tigecycline for the treatment of complicated skin and soft-tissue and intra-abdominal infections: an analysis based on five European observational studies. J Antimicrob Chemother 2013;68:Suppl 2:ii37-ii44.

11. Samuelsson A, Isaksson B, Chabok A, et al. Changes in the aerobic faecal flora of patients treated with antibiotics for acute intra-abdominal infection. Scand J Infect Dis 2012;44:820-7.

12. Marshall JC, Maier RV, Jimenez M, Dellinger EP. Source control in the management of severe sepsis and septic shock: an evidence-based review. Crit Care Med 2004;32:Suppl:S513-S526.

13. Sursal T, Stearns-Kurosawa DJ, Itagaki K, et al. Plasma bacterial and mitochondrial DNA distinguish bacterial sepsis from sterile systemic inflammatory response syndrome and quantify inflammatory tissue injury in nonhuman primates. Shock 2013;39:55-62.

14. Turnbull IR, Javadi P, Buchman TG, Hotchkiss RS, Karl IE, Coopersmith CM. Antibiotics improve survival in sepsis independent of injury severity but do not change mortality in mice with markedly elevated interleukin 6 levels. Shock 2004; 21:121-5

15. Wong YY, Wong PN, Mak SK, et al. 
Persistent sterile peritoneal inflammation after catheter removal for refractory bacterial peritonitis predicts full-blown encapsulating peritoneal sclerosis. Perit Dial Int 2013;33:507-14.

16. Chastre J, Wolff M, Fagon JY, et al. Comparison of 8 vs 15 days of antibiotic therapy for ventilator-associated pneumo- nia in adults: a randomized trial. JAMA 2003;290:2588-98.

17. Basoli A, Chirletti P, Cirino E, et al. A prospective, double-blind, multicenter, randomized trial comparing ertapenem 3 vs $>$ or $=5$ days in community-acquired intraabdominal infection. J Gastrointest Surg 2008;12:592-600.
18. Dellinger RP, Levy MM, Rhodes A, et al. Surviving sepsis campaign: international guidelines for management of severe sepsis and septic shock: 2012. Crit Care Med 2013;41:580-637.

Copyright @ 2015 Massachusetts Medical Society. 